\title{
The emerging role of anti-angiogenic therapy in ovarian cancer (Review)
}

\author{
VINCENZA CONTEDUCA ${ }^{1}$, BARBARA KOPF ${ }^{2}$, SALVATORE LUCA BURGIO $^{1}$, \\ EMANUELA BIANCHI $^{1}$, DINO AMADORI ${ }^{1}$ and UGO DE GIORGI ${ }^{1}$
}

${ }^{1}$ Department of Medical Oncology, Istituto Scientifico Romagnolo per lo Studio e la Cura dei Tumori (I.R.S.T.) - IRCCS,
Meldola (FC), Italy; ${ }^{2}$ Istituto Oncologico della Svizzera Italiana (IOSI), Ospedale San Giovanni, Bellinzona, Switzerland

Received December 8, 2013; Accepted January 28, 2014

DOI: 10.3892/ijo.2014.2334

\begin{abstract}
The introduction of new therapeutic agents into clinical practice of ovarian cancer, in addition to the role of surgery and chemotherapy, has been the subject of numerous studies because this tumor remains worldwide the most lethal gynecological cancer. It is now known that angiogenesis plays a vital role for ovarian physiology, but also in ovarian carcinogenesis and so it has become the main target of ovarian cancer treatment. In this review, the most common molecular pathways of angiogenesis have been investigated leading to the identification of novel targets, including monoclonal antibodies and tyrosine kinase inhibitors. The fundamental targets of anti-angiogenic drugs are vascular endothelial growth factor receptor and its ligand, but also platelet-derived growth factor, fibroblast growth factor and angiopoietin. Moreover, improved knowledge of angiogenic process allowed the discovery of other molecules, such as semaphorins, neuropilins, clusterin, some transcriptional factors, and the identification of features, including stemness, epithelialmesenchymal transition, downregulation of certain microRNAs,
\end{abstract}

Correspondence to: Dr Vincenza Conteduca, Department of Medical Oncology, Istituto Scientifico Romagnolo per lo Studio e la Cura dei Tumori (I.R.S.T.) - IRCCS, Via Piero Maroncelli 40, I-47014 Meldola (FC), Italy

E-mail: cinzia.conteduca@libero.it

Abbreviations: Ca125, carbohydrate antigen-125; CSC, cancer stem cells; CXCR4, chemokine receptor-4; EGFR, epidermal growth factor receptor; EOC, epithelial ovarian cancer; EMT, epithelial to mesenchymal transition; FGF, fibroblast growth factor; HE-4, human epididymis protein-4; HER-2, human epidermal growth factor receptor-2; HIF, hypoxia-inducible factor; IL, interleukin; miRNA, microRNA; mTOR, mammalian target of rapamycin; OS, overall survival; PDGFR, platelet-derived growth factor receptor; PFS, progression free survival; SDF-1, stromal cell-derived factor-1; TGF- $\beta$, transforming growth factor- $\beta$; VEGFR, vascular endothelial growth factor receptor

Key words: epithelial ovarian cancer, angiogenesis, vascular endothelial growth factor, bevacizumab, chemotherapy, monoclonal antibody, tyrosine kinase inhibitor the alteration of immune system, that contribute to angiogenesis and possibly to resistance mechanisms. The following patent and literature review aim to highlight recent findings of approved and novel anti-angiogenic drugs that make the treatment of patients with ovarian cancer a rapidly growing field of oncology.

\section{Contents}

1. Introduction

2. Angiogenesis in ovarian cancer

3. Bevacizumab in ovarian cancer

4. Novel drugs targeting angiogenesis through alternative pathways

5. Current and future developments

\section{Introduction}

Ovarian cancer is the most common cause of cancer deaths in women affected by gynecologic tumors. Worldwide, ovarian cancer is diagnosed in 225,000 women each year and accounts for over 125,000 deaths (1). Incidence rates vary greatly depending on the geographic distribution and age; most epithelial ovarian cancer (EOC) is diagnosed in developed countries and in women at the sixth and seventh decades of life (2). EOC is characterized by poor prognosis, resulting in 5 -year survival rate of only $30 \%$, because diagnosis is often late (approximately $70 \%$ of cases are diagnosed at advanced stage) due to vague initial signs and symptoms. In addition, disease recurrence is frequent in over 70-80\% of EOC, despite optimal cytoreduction and adequate adjuvant therapy $(3,4)$. Therefore, new therapeutic strategies are needed to improve outcome of ovarian cancer patients and overcome resistance mechanisms. Targeted therapy represents a viable option for management of these patients; especially angiogenesis inhibitors have shown promising therapeutic results in ovarian cancer, in combination with chemotherapy and also as monotherapy.

\section{Angiogenesis in ovarian cancer}

Angiogenesis is a multi-step process essential for tumor growth and metastasis, which involves endothelial cell proliferation, 
migration and capillary formation. It is responsible for tumor growth through the diffusion of nutrients and oxygen from adjacent capillaries (5-7). Hypoxic state induces pro-angiogenic signaling by activating a protein called hypoxia-inducible factor (HIF) $-1 \alpha$ which enters the nucleus and forms a complex with another protein, the HIF-1 $\beta$. HIF-1 complex plays as a transcription factor targeting many genes responsible of upregulation of growth factors, such as vascular endothelial growth factor (VEGF), fibroblast growth factor-2 (FGF-2), platelet-derived growth factor (PDGF) and their receptors and downregulation of anti-angiogenic factors such as thrombospondin-1 and angiostatin. In addition, HIF-1 targets also other genes involved in different steps of the angiogenic process through matrix remodeling factors (e.g. matrix metalloproteases) and factors mediating the migration/invasion of bone-marrow derived cells, including chemokine receptor CXCR4 and its specific ligand, stromal cell-derived factor-1 (CXCR4/SDF-1) axis involved in tumor neoangiogenesis (8).

Among several pro-angiogenic factors, VEGF plays a crucial role in the proliferation, migration and survival of vascular endothelial cells leading to tumor growth and metastasis development (9-12), also through a direct, autocrine effect on tumor cells (13). Some studies have shown a direct role of VEGF-A in cell proliferation and invasiveness also through AKT/mTOR pathway and by altering the expression of matrix metalloproteinase-2 (14,15).

VEGF levels are elevated in malignant ovarian tumors and so it could be used as a biomarker in combination with other proteins, including carbohydrate antigen-125 (Ca125) or human epididymis protein-4 (HE-4) (16,17). The VEGF expression is able to classify $100 \%$ of ovarian cancer of various histotypes (18). High levels of VEGF in ovarian cancer patients is associated with advanced tumor stage $(19,20)$, major incidence of metastases (19), poor progression-free survival (PFS) and overall survival (OS) (21). In addition, it has been demonstrated that VEGF overexpression is correlated with the formation of ascites, carcinomatosis and poor prognosis in ovarian cancer. In preclinical models, the use of an anti-VEGF antibody prevented and reserved the presentation of ascites $(22,23)$, and also its combination with paclitaxel reduced surviving levels (24). On the other hand, anti-angiogenic agents inhibit new blood vessel growth and the haematopoietic and endothelial progenitor cell incorporation, normalize the vasculature and induce endothelial cell apoptosis (25).

Semaphorins and neuropilins are molecules involved in angiogenesis and in ovarian carcinogenesis process. Neuropilins bind to the commonest isoform of VEGF-A and may act as co-receptors to enhance VEGF signaling through VEGFR-1. Semaphorins regulate negatively angiogenesis and EOC patients with a high $\mathrm{VEGF} / \mathrm{semaphorin}$ ratio have a poor survival, because the reduced expression of semaphorins may play an important role in ovarian cancer progression (26).

In EOC, it has been demonstrated that the overexpression of clusterin, a multivalent glycoprotein with ubiquitous tissue distribution, could be correlated with increased tumor angiogenesis, acting probably as an oncogene in the biology of ovarian cancer (27).

In addition, in EOC, as in other tumors, changes in transcriptional regulation can lead to malignant transformation by causing deregulated cell proliferation, suppression of apop- tosis, increased angiogenesis. The Jun proteins (c-Jun, JunD and JunB), like Fos proteins, act as transcription factors by forming heterodimers with Jun proteins are important players in angiogenesis and cellular regulation, enhancing cell proliferation, protecting cells from apoptosis. Jun proteins have also tumor-suppressing functions. In fact, the downregulation of JunD can reduce cell proliferation, Ras-induced malignant transformation and to inhibit tumor-related angiogenesis. So Jun and Fos proteins might also be suitable prognostic factors and therapeutic targets $(28,29)$.

Recent evidence supports the role of ovarian cancer stem cells (CSC), that may be characterized by the combined expression of numerous putative cell surface and intracellular markers, including CD44, epithelial cell adhesion molecule, CD133, CD117, CD90 (Thy-1), CD24 and the intracellular marker (ALDH). CD133 ${ }^{+} \mathrm{ALDH}^{+}$human ovarian CSC were highly angiogenic because they derive from tumor metastases capable of attracting endothelial progenitors to promote angiogenesis (30-32). Another study demonstrated that xenograft tumors derived from CD $44^{+}$cells had human CD34 expressing blood vessels suggesting that human ovarian $\mathrm{CD} 44^{+} \mathrm{CSC}$ might have the potential to differentiate into vessels or direct other cells for the formation of vessel cells (33). The relation between angiogenesis and stemness can be reciprocal; not only can CSC regulate angiogenesis but recent studies have also reported that hypoxia may be one of the key attributes in the tumor microenvironment which can regulate the phenotype of CSCs through the activation of oncogenes such as myc and ras, resulting in the expression of HIF-1 and HIF-2 inducing the expression of pluripotent genes such as Oct4, Sox 3 and kruppel-like factor-4 $(34,35)$. Hypoxia has been shown to induce epithelial to mesenchymal transition (EMT), a process characterized by the transformation of differentiated epithelial cells into migratory mesenchymal cells, in ovarian CSCs by triggering TWIST1 expression (36) or by autocrine secretion of the transforming growth factor (TGF)- $\beta$ (37). In addition, cyclin D1 might be involved in sustaining the mesenchymal features of ovarian cancer stem cell-like cells in EMT (38).

Currently, apart from VEGF, many studies are ongoing to identify other molecules and pathways involved in angiogenesis, because angiogenetic process has been established as an important step in carcinogenesis influencing tumor growth and the development of metastases.

Among the novel factors contributing to angiogenetic mechanisms in ovarian cancer, CD147, an extracellular matrix metalloproteinase inducer, has been identified to be overexpressed in ovarian cancers and its gene has two hypoxiainducible factors binding sites. The hypoxic microenvironment constitutes a greater inducer of the overexpression of CD147, which is present in microvesicles derived from epithelial ovarian cancer cells that could promote an angiogenic phenotype in endothelial cells (39-41).

Lysyl oxidase-like-2 (42), among the pro-angiogenetic molecules, is a secreted enzyme which catalyzes the crosslinking of collagen, inhibitor of DNA binding/differentiation-1 (Id1) (43), enhancing human ovarian cancer endothelial progenitor cell proliferation via PI3K/Akt and NF- $\kappa \mathrm{B} /$ metalloproteinase-2 (MMP-2) signaling pathways.

There is increasing evidence for epigenetic control of angiogenesis by non-coding microRNAs (miRNAs), which 
activate messenger RNA degradation or block translation Endothelial cells express several miRNAs, often induced by hypoxia or VEGF, that have been shown to be involved in angiogenesis of many tumors, including ovarian cancer (44). Two miRNAs, miRNA-199a and miRNA-125b, have been demonstrated to be downregulated in ovarian cancer tissues and cell lines, whereas their overexpression could inhibit tumor-induced angiogenesis through the reduction of HIF-1 $\alpha$ and VEGF expression in ovarian cancer cells (45).

Recently, it has been suggested that immune system and angiogenesis could display a reciprocal action. VEGF also exerts an immunosuppressive effect in ovarian cancer through VEGFR2, which is expressed by activated lymphocytes; in fact it is correlated with low levels of IL-12, inhibition of dendritic cell maturation, reduced number of natural killer-T cells and upregulation of regulatory $\mathrm{T}$ cells. Moreover, it has been established that the interaction of EOC cells and tumor-associated macrophages lead endothelial cells to promote angiogenesis and to infiltrate the peritoneum, that represent the dominant clinical features of this cancer (46-48).

\section{Bevacizumab in ovarian cancer}

Bevacizumab is a recombinant humanized monoclonal IgG1 antibody that binds to and neutralizes all biologically active forms of VEGF-A, and so inhibits tumor growth and metastatic disease progression (49). The utility of bevacizumab in combination with chemotherapy is demonstrated in the treatment of many epithelial malignancies cancer, including EOC. Initially bevacizumab was explored in animal models, where it inhibited ascites formation and slowed tumor growth (23). In addition, bevacizumab and other VEGF-targeting agents were able to enhance the effects of chemotherapy by normalization of primitive tumor vasculature with reduction of interstitial fluid pressure, increase of tumor oxygenation, major delivery of cytotoxic drugs (50).

Currently, bevacizumab is the most studied anti-angiogenic drug in EOC in different tumor settings. In addition, it is usually associated with cytotoxic drugs in phase III and phase II studies, but in the past has also been used as monotherapy and some phase II studies of combination of bevacizumab with other anti-angiogenic molecules are ongoing.

Bevacizumab in combination with chemotherapy. Two phase III randomized trials have recently evaluated the addition of bevacizumab to the standard paclitaxel/carboplatin and maintenance therapy with bevacizumab at the end of chemotherapy.

GOG-0218 (51) is a three-arm trial comparing carboplatin and paclitaxel versus carboplatin, paclitaxel and bevacizumab plus or minus maintenance bevacizumab. This trial examined 1,873 patients with advanced (stage III-IV) EOC. PFS was the primary end-point and it was significantly longer in the carboplatin, paclitaxel, bevacizumab and maintenance bevacizumab group compared with the two other groups (median PFS 10.3 months for control; 11.2 months for bevacizumab and chemotherapy plus placebo maintenance; 14.1 months for bevacizumab and chemotherapy plus bevacizumab maintenance). The International Collaborative Ovarian Neoplasm (ICON) 7 study (52) is a two-arm trial comparing carboplatin and paclitaxel versus carboplatin, paclitaxel and bevacizumab followed by maintenance bevacizumab. The trial included 1,528 women with stage IIB-IV disease as well as stage I-IIA disease who have grade 3 or clear cell histology. The primary end-point was PFS, that was significantly better in the bevacizumab arm (PFS at 36 months: 20.3 months in control arm vs. 21.8 months in bevacizumab arm). The results of these studies led to the approval of bevacizumab by European Medicines Agency (EMEA) for first-line treatment of FIGO stage IIIB, IIIC and IV EOC.

Bevacizumab has been also evaluated in relapsed EOC. OCEANS trial (53) is a 2-arm, double-blind study of 484 women with platinum-sensitive recurrent EOC after first-line chemotherapy. This study compared bevacizumab plus carboplatin/gemcitabine with carboplatin/gemcitabine alone. The primary end-point was PFS, which was significantly prolonged by the addition of bevacizumab by 4 months. AURELIA trial (54) is a randomized phase III trial evaluating bevacizumab plus chemotherapy (pegylated liposomal doxorubicin, topotecan, or weekly paclitaxel) in 361 platinum-resistant patients with recurrent EOC. This study concluded that the addition of bevacizumab to chemotherapy in platinum resistant OC provides statistically significant improvement in PFS compared to chemotherapy alone (6.7 months versus 3.4 months, respectively).

Several clinical trials have demonstrated the safety and activity of bevacizumab in combination with cytotoxic chemotherapy agents typically used in platinum-resistant EOC: topotecan, pegylated liposomal doxorubicin, weekly paclitaxel, nab-paclitaxel, low-dose metronomic oral cyclophosphamide (55-60). As summarized in Table I, these studies show that the combination is safe and active in platinum-resistant EOC and suggest bevacizumab may enhance the efficacy of the cytotoxic agent with PFS ranging from 2.8 and 13.9 months, overall survival from 2.8 to 33.2 months, objective rates from 24 to $72.2 \%$. A recent phase II trial (61) of pegylated liposomal doxorubicin and carboplatin plus bevacizumab has showed objective rate of over $70 \%$ with PFS of 13.9 months in patients with platinum-sensitive recurrent EOC.

Single-agent bevacizumab. Two phase II studies $(62,63)$ evaluated also efficacy of single-agent bevacizumab in platinum-pretreated patients with recurrent EOC, reporting acceptable results. The first trial (62), termed GOG-0170D, reported an overall response rate of $21 \%$ and median PFS and OS of 4.7 and 17 months in 62 persistent or recurrent EOC or primary peritoneal cancers treated with bevacizumab monotherapy every three weeks. The second study (63), evaluating the efficacy and safety of bevacizumab monotherapy in 44 patients with platinum-resistant EOC who had experienced disease progression during or within 3 months of discontinuing topotecan or pegylated liposomal doxorubicin, showed an objective response rate of $15.9 \%$, median PFS of 4.4 months and median OS of 10.7 months.

Bevacizumab plus other target therapies. Some trials have considered the opportunity of combining bevacizumab with other non-anti-angiogenic biologic agents leading so far to disappointing and inconclusive results in platinum sensitive and platinum-resistant patients. The studies $(64,65)$ evaluating bevacizumab plus erlotinib showed response rates between $15 \%$ and $23 \%$ and PFS of about 4 months. However, the first 
Table I. Phase III and II trials of bevacizumab in patients with epithelial ovarian cancer.

\begin{tabular}{|c|c|c|c|c|c|c|}
\hline $\begin{array}{l}\text { Trial } \\
\text { author/(refs.) }\end{array}$ & $\begin{array}{c}\text { Phase } \\
\text { trial }\end{array}$ & $\begin{array}{c}\text { Patient } \\
\text { population }\end{array}$ & Arm & $\begin{array}{c}\text { PFS } \\
\text { (months) }\end{array}$ & $\begin{array}{c}\text { OS } \\
\text { (months) }\end{array}$ & $\begin{array}{l}\mathrm{RR} \\
(\%)\end{array}$ \\
\hline
\end{tabular}

Chemotherapy plus bevacizumab

First line

GOG-0218
Burger et al (51)

ICON7

Perren et al (52)

Relapse

OCEANS

Aghajanian et al (53)

AURELIA

Pujane-Lauraine et al (54)

NCI-5789

Garcia et al (55)

McGonigle et al (56)

Kudoh et al (57)

O'Malley et al (58)

Verschraegen et al (59)

Tillmanns et al (60)

Del Carmen et al (61)
III

III

III

III

II

II

II

II

II

II

II

II
1,873

1,528

484

Platinum-sensitive

361

Platinum-resistant 70

Platinum-resistant 40

Platinum-resistant

30

Platinum-resistant

$$
41
$$

Platinum-resistant 46

Platinum-resistant 48

Platinum-resistant 54

Platinum-sensitive

\begin{tabular}{|c|c|c|c|}
\hline $\mathrm{CT}$ & 10.3 & 39.3 & \\
\hline $\mathrm{CT}+\mathrm{BEV}$ & 11.2 & 38.7 & NR \\
\hline $\mathrm{CT}+\mathrm{BEV}>\mathrm{BEV}$ & 14.1 & 39.7 & \\
\hline $\mathrm{CT}$ & 22.4 & 28.8 & 48 \\
\hline $\mathrm{CT}+\mathrm{BEV}>\mathrm{BEV}$ & 24.1 & 36.6 & 67 \\
\hline $\mathrm{CG}$ & 8.4 & 35.2 & 57.4 \\
\hline $\mathrm{CG}+\mathrm{BEV}$ & 12.4 & 33.3 & 78.5 \\
\hline P/T/PLD & 3.4 & NR & 2.6 \\
\hline $\mathrm{P} / \mathrm{T} / \mathrm{PLDD}+\mathrm{BEV}$ & 6.7 & NR & 30.9 \\
\hline $\mathrm{Cy}+\mathrm{Bev}$ & 7.2 (TTP) & NR & 24 \\
\hline $\mathrm{T}+\mathrm{Bev}$ & $\begin{array}{l}10.9 \text { (1 prior } \\
\text { regimen) }\end{array}$ & $\begin{array}{l}22.9 \text { (1 prior } \\
\text { regimen) }\end{array}$ & 25 \\
\hline & $\begin{array}{l}2.8(2 \text { prior } \\
\text { regimens })\end{array}$ & $\begin{array}{c}2.8 \text { ( } 2 \text { prior } \\
\text { regimens })\end{array}$ & \\
\hline PLD+Bev & 6 & NR & 33 \\
\hline $\mathrm{P}+\mathrm{Bev}$ & 13.2 & 20.6 & 63 \\
\hline $\mathrm{P}$ & 6.2 & 9.1 & \\
\hline PLD+Bev & 7.8 & 33.2 & 30.2 \\
\hline $\mathrm{Nab}-\mathrm{P}+\mathrm{Bev}$ & 8.08 & 17.15 & 50 \\
\hline $\mathrm{PLD}+\mathrm{C}+\mathrm{Bev}$ & 13.9 & NR & 72.2 \\
\hline
\end{tabular}

Single-agent bevacizumab

\section{Relapse}

GOG-0170D

Burger et al (62)

Genentech_AVF 2949g

Cannistra et al (63)
II

II

II

Platinum-sensitive and platinum-resistant Primary peritoneal cancer

Platinum-sensitive and platinum-resistant Primary peritoneal cancer
$44 \quad$ Bev
Bev
4.7

17

21

\section{Bevacizumab plus other target therapies}

\begin{tabular}{|c|c|c|c|c|c|c|}
\hline Nimeiri et al (64) & II & $\begin{array}{l}13 \\
\text { Platinum-sensitive } \\
\text { and platinum-resistant }\end{array}$ & Bev+erlotinib & 4.1 & 11 & 15.1 \\
\hline Chambers et al (65) & II & $\begin{array}{l}40 \\
\text { Platinum-sensitive } \\
\text { and platinum-resistant }\end{array}$ & Bev+erlotinib & 4 & NR & 23.1 \\
\hline Morgan et al (66) & II & $\begin{array}{l}31 \\
\text { Platinum-sensitive } \\
\text { and platinum-resistant }\end{array}$ & $\begin{array}{c}\text { Bev+ } \\
\text { temsirolimus }\end{array}$ & $\begin{array}{c}56 \% \\
\text { (6-mo PFS) }\end{array}$ & NR & 12 \\
\hline Kohn et al (67) & II & $\begin{array}{c}30 \\
\text { Bev-naïve patients }\end{array}$ & Bev+sorafenib & NR & NR & 24 \\
\hline
\end{tabular}

PFS, progression-free survival, OS, overall survival; GOG, Gynecologic Oncology Group; ICON, International Co-operative Group for Ovarian Neoplasia; C, carboplatin; P, paclitaxel; Bev, bevacizumab; G, gemcitabine; T, topotecan; PLD, pegylated liposomal doxorubicin; Cy, cyclophosphamide; NR, not reported. 


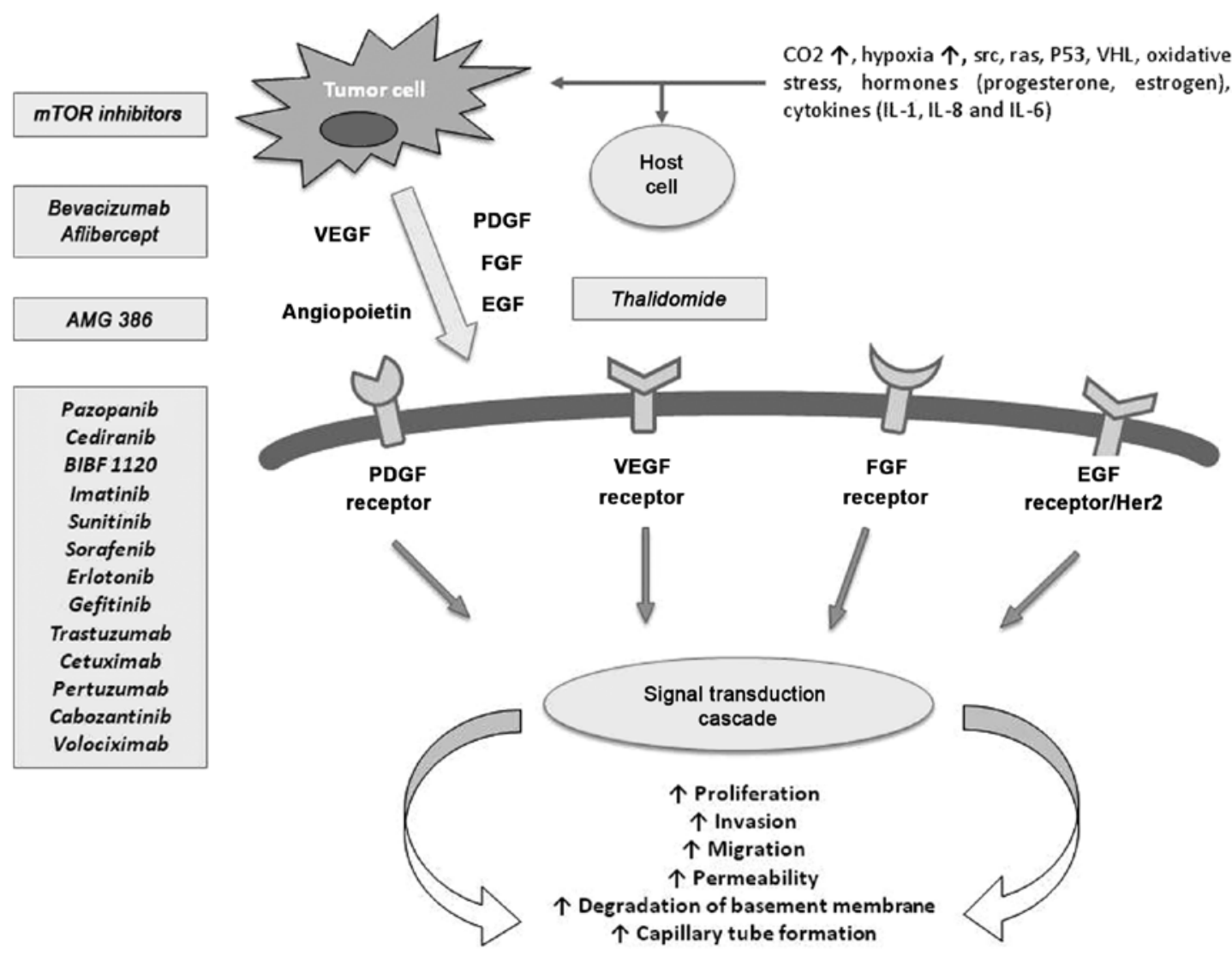

Figure 1. Main mechanisms of angiogenesis in ovarian cancer and agents targeting angiogenesis through VEGF pathway and alternative pathways under evaluation in phase II-III trials.

study (64) was closed prematurely for two fatal gastrointestinal perforations and the second (65) concluded that the addition of erlotinib did not seem to contribute to efficacy.

A phase II study combined bevacizumab with temsirolimus in recurrent ovarian cancer reporting an objective response rate of $12 \%$ (66), whereas another trial, combining bevacizumab with sorafenib in bevacizumab naïve epithelial EOC patients, showed a response rate of $24 \%$ (all partial responses) (67).

\section{Novel drugs targeting angiogenesis through alternative pathways}

Blocking angiogenesis represents an effective therapeutic strategy leading to control EOC tumor growth. There are two primary strategies to inhibit the VEGF pathway: inhibition of the VEGF ligand with antibodies or soluble receptors and inhibition of the VEGFR with tyrosine kinase inhibitors (TKI) or receptor antibodies. Moreover, some studies are evaluating new drugs targeting multiple angiogenic pathways, including the PDGF and FGF pathways that could counteract resistance mechanisms and so enhance anti-angiogenic and antiproliferative effects (Fig. 1). Among drugs targeting VEGF pathway, there is VEGF Trap (aflibercept), a fusion protein consisting of the extracellular binding domains of human VEGF-1 and -2 linked through the $\mathrm{Fc}$ region of human IgG1. Aflibercept acts through VEGFA binding and neutralizing all VEGFA isoforms. A phase II study evaluating 162 patients with recurrent, platinum-resistant EOC showed similar response rates compared with bevacizumab administration (11\% partial response), with acceptable toxicity profile and low incidence of bowel perforation $(1 \%)(68,69)$.

There are now several small molecule inhibitors of VEGFR TKI inhibiting the VEGFR family and others, such as PDGFR, c-kit, which could be active in ovarian cancer. Pazopanib is a TKI that targets VEGFR-1, VEGFR-2, VEGFR-3, PDGFR- $\alpha$, PDGFR- $\beta$, and c-Kit was used in asymptomatic relapse with increasing Ca125, following complete response after first-line chemotherapy. The primary end-point was Ca125 response that was reported in $31 \%$ of cases (70). Subsequently, some studies have evaluated efficacy and safety of pazopanib in combination with cytotoxic drugs, as paclitaxel, carboplatin, cyclophosphamide, leading to controversial results.

Cediranib (AZD2171), an oral VEGFR-1, -2 and -3, PDGFRB and c-kit inhibitor, showed 17\% objective response rates as monotherapy (71). Most patients (65\%) had platinum-resistant disease. Currently, the ICON 6 trial is studying cediranib in platinum-sensitive patients with first relapse.

Sunitinib, an oral multi-target VEGF and PDGF receptor tyrosine kinase inhibitor with anti-angiogenic and antitumor activity, has been used in a phase II study of 30 recurrent ovarian cancer patients with a partial response and Ca125 response less than $10 \%$. These results were observed only in platinum sensitive patients that represented $72 \%$ of all patients (72).

Sorafenib is a small molecule which inhibits cell proliferation by targeting the MEK/ERK signaling pathway through 
the inhibition of Raf-1 kinase and by inhibiting VEGF receptors. Several studies using sorafenib have been reported, but as monotherapy (73) or in combination with other cytotoxic agents (74-76), including gemcitabine, carboplatin, paclitaxel, topotecan, have shown limited efficacy in recurrent disease with often severe toxicities. Probably the most promising results with sorafenib have been reported in a study of sorafenib/bevacizumab combination (67).

Nintedanib (BIBF1120) is a triple TKI against VEGFR, PDGFR and FGFR. In a randomised maintenance trial nintedanib (BIBF1120)/placebo was given to patients who had responded and completed treatment for relapsed disease, with evidence of response ( $16 \%$ in patients receiving nintedanib and $5 \%$ on placebo), but at high risk of further early recurrence (77).

Cabozantinib, a highly potent TKI directed against VEGFR2 and the hepatocyte growth factor (HGF) receptor c-Met, has promising single-agent activity in recurrent ovarian cancer with a $24 \%$ objective response rate (78).

Imatinib mesylate inhibits abl, c-kit and PDGFR tyrosine kinases, but different phase II trials of imatinib mesylate in recurrent ovarian cancer showed no complete or partial responders (79).

Several EGFR and HER-2 inhibitors are also being tested in patients with ovarian cancer (erlotinib, gefitinib, trastuzumab, pertuzumab, cetuximab), but have shown only modest efficacy both in monotherapy and in association with other cytotoxic agents and bevacizumab.

Angiopoietins are circulating protein growth factors (Ang-1/Ang-2) that promote angiogenesis by binding Tie2 receptors. A recent phase II randomized trial demonstrated activity for the selective angiopoietin 1/2-neutralizing peptibody, AMG 386, a peptide-Fc fusion protein that blocks the interaction between the Tie2 receptor and angiopoietin-1/2. A study evaluating AMG386 in combination with weekly paclitaxel showed prolongation of PFS (from 4.6 to 7.2 months, HR 0.76) (80). Currently, AMG386 is being tested in phase III trials both in first line (TRINOVA-3; NCT01493505) with carboplatin and paclitaxel and in the recurrent disease in combination with weekly paclitaxel (TRINOVA-1; NCT01204749).

Thalidomide has been demonstrated to have anti-angiogenic properties by blocking fibroblast growth factor and VEGF-induced angiogenesis. It also modulates the immune system by inducing production of interferon- $\gamma$, interleukin- 2 , and interleukin-10. A phase II trial has evaluated the efficacy of thalidomide plus topotecan in 69 women with recurrent EOC. The response rate for the group with thalidomide was 47 vs. $21 \%$ in the control group and PFS was significantly higher of two months for the thalidomide group (6 vs. 4 months), with similar toxicities (81). However, a study on thalidomide compared to tamoxifen did not show any activity on disease progression for maintenance therapy after complete remission from initial surgery and chemotherapy (82).

Volociximab (M200) is a monoclonal antibody that specifically binds integrins, which are important transmembrane proteins for vasculogenesis. Pre-clinical testing showed inhibition of proliferating endothelial cells by volociximab. However, a phase II, single-arm study of volociximab as monotherapy in patients with platinum-resistant advanced epithelial ovarian has showed insufficient clinical activity of volociximab (83).

\section{Current and future developments}

The most experience of anti-angiogenic therapy for patients with EOC resulted from the use of bevacizumab, but yet several trials are ongoing for identifying novel anti-angiogenic agents for EOC treatment in different setting. A better knowledge of several pathways involved in angiogenesis can help to select patients who might benefit from anti-angiogenic therapy with the discovery of predictive biomarkers and the identification of likely mechanisms of resistance to chemotherapy or targeted therapy, thus making anti-angiogenic therapies acceptable in terms of cost-effectiveness. Finally, future studies will need to focus also on optimal timing of anti-angiogenic agents and on possible combination of multiple targeted agents and/or cytotoxic chemotherapies. Despite the many unresolved questions, there is a growing body of evidence that targeting angiogenesis will lead to improved outcomes for women with ovarian cancer.

\section{References}

1. Ferlay J, Shin H-R, Bray F, Forman D, Mathers C and Parkin DM: Estimates of worldwide burden of cancer in 2008: GLOBOCAN 2008. Int J Cancer 127: 2893-2917, 2010.

2. Jelovac D and Armstrong DK: Recent progress in the diagnosis and treatment of ovarian cancer. CA Cancer J Clin 61: 183-203, 2011.

3. Jemal A, Siegel R, Ward E, Hao Y, Xu J, Murray T and Thun MJ: Cancer statistics, 2008. CA Cancer J Clin 58: 71-96, 2008.

4. Howlader N, Noone AM, Krapcho M, Garshell J, Neyman N, Altekruse SF, Kosary CL, et al: SEER Cancer Statistics Review, 1975-2010, National Cancer Institute. Bethesda, MD, http://seer. cancer.gov/csr/1975_2010/, based on November 2012 SEER data submission, posted to the SEER web site, 2013.

5. Folkman J: Tumor angiogenesis. Therapeutic implications. N Engl J Med 285: 1182-1186, 1971.

6. Conway E-M, Collen D and Carmeliet P: Molecular mechanisms of blood vessel growth. Cardiovasc Res 49: 507-521, 2001.

7. Chavakis E and Dimmeler S: Regulation of endothelial cell survival and apoptosis during angiogenesis. Arterioscler Thromb Vasc Biol 22: 887-893, 2002.

8. Van der Bilt AR, de Vries EG, de Jong S, Timmer-Bosscha H, van der Zee AG and Reyners AK: Turning promise into progress for antiangiogenic agents in epithelial ovarian cancer. Crit Rev Oncol Hematol 84: 224-242, 2012.

9. Claesson-Welsh L and Welsh M: VEGFA and tumour angiogenesis. J Intern Med 273: 114-127, 2013.

10. Olsson AK, Dimberg A, Kreuger J and Claesson-Welsh L: VEGF receptor signalling - in control of vascular function. Nat Rev Mol Cell Biol 7: 359-371, 2006.

11. Hicklin DJ and Ellis LM: Role of the vascular endothelial growth factor pathway in tumor growth and angiogenesis. J Clin Oncol 23: 1011-1027, 2005.

12. Kaplan RN, Riba RD, Zacharoulis S, Bramley AH, Vinent L, Costa C, MacDonald DD, et al: VEGFR1-positive haematopoietic bone marrow progenitors initiate the pre-metastatic niche. Nature 6: 820-827, 2005.

13. Lichtenberger BM, Tan PK, Niederleithner H, Ferrara N, Petzelbauer $\mathrm{P}$ and Sibilia M: Autocrine VEGF signaling synergizes with EGFR in tumor cells to promote epithelial cancer development. Cell 6: 268-279, 2010.

14. Trinh XB, Tjalma WA, Vermeulen PB, Van den Eynden G, Van der Auwera I, Van Laere SJ, Helleman J, et al: The VEGF pathway and the AKT/mTOR/p70S6K1 signalling pathway in human epithelial ovarian cancer. Br J Cancer 100: 971-978, 2009.

15. Zhang A, Meng L, Wang Q, Chen G, Wang S, Zhou J, Lu Y, et al: Enhanced in vitro invasiveness of ovarian cancer cells through up-regulation of VEGF and induction of MMP-2. Oncol Rep 15: 831-836, 2006.

16. Artini PG, Ruggiero M, Monteleone P, Carpi A, Cristello F, Cela V, Genazzani AR, et al: Vascular endothelial growth factor and its soluble receptor in benign and malignant ovarian tumors. Biomed Pharmacother 62: 373-377, 2008. 
17. Lawicki S, Bedkowska GE, Gacuta-Szumarska E and Szmitkowski M: The plasma concentration of VEGF, HE4 and CA125 as a new biomarkers panel in different stages and sub-types of epithelial ovarian tumors. J Ovarian Res 6: 45, 2013.

18. Lu KH, Patterson AP, Wang L, Marquez RT, Atkinson EN, Baggerly KA, Ramoth LR, et al: Selection of potential markers for epithelial ovarian cancer with gene expression arrays and recursive descent partition analysis. Clin Cancer Res 10: 3291-3300, 2004.

19. Li L, Wang L, Zhang W, Tang B, Zhang J, Song H, Yao D, et al: Correlation of serum VEGF levels with clinical stage, therapy efficacy, tumor metastasis and patient survival in ovarian cancer. Anticancer Res 24: 1973-1979, 2004.

20. Rudlowski C, Pickart AK, Fuhljahn C, Friepoertner T, Schlehe B, Biesterfeld S and Schroeder W: Prognostic significance of vascular endothelial growth factor expression in ovarian cancer patients: a long-term follow-up. Int J Gynecol Cancer 16: 183-189, 2006.

21. Yu L, Deng L, Li J, Zhang Y and Hu L: The prognostic value of vascular endothelial growth factor in ovarian cancer: a systematic review and meta-analysis. Gynecol Oncol 128: 391-396, 2013

22. Hu L, Hoffmann J, Zaloudak C, Ferrara N, Hamilton T and Jaffe RB: Vascular endothelial growth factor immunoneutralization plus paclitaxel markedly reduces tumor burden and ascites in athymic mouse model of ovarian cancer. Am J Pathol 161: 1917-1924, 2002.

23. Byrne AT, Ross L, Holash J, Nakanishi M, Hu L, Hofmann JI, Yancopoulos GD, et al: Vascular endothelial growth factor-trap decreases tumor burden, inhibits ascites, and causes dramatic vascular remodeling in an ovarian cancer model. Clin Cancer Res 9: 5721-5728, 2003

24. Tran J, Master Z, Yu JL, Rak J, Dumont DJ and Kerbel RS: A role of surviving in chemoresistance of endothelial cells mediated by VEGF. Proc Natl Acad Sci USA 99: 4349-4354, 2002.

25. Martin L and Schilder R: Novel approaches in advancing the treatment of epithelial ovarian cancer: the role of angiogenesis inhibition. J Clin Oncol 25: 2894-2901, 2007.

26. Osada R, Horiuchi A, Kikuchi N, Ohira S, Ota M, Katsuyama Y and Konishi I: Expression of semaphorins, vascular endothelial growth factor, and their common receptor neuropilins and alleic loss of semaphorin locus in epithelial ovarian neoplasms: increased ratio of vascular endothelial growth factor to semaphorin is a poor prognostic factor in ovarian carcinomas. Hum Pathol 37: 1414-1425, 2006.

27. Fu Y, Lai Y, Wang Q, Liu X, He W, Zhang H, Fan C, et al: Overexpression of clusterin promotes angiogenesis via the vascular endothelial growth factor in primary ovarian cancer. Mol Med Rep 7: 1726-1732, 2013.

28. Eckhoff K, Flurschütz R, Trillsch F, Mahner S, Jänicke F and Milde-Langosch K: The prognostic significance of Jun transcription factors in ovarian cancer. J Cancer Res Clin Oncol 139: 1673-1680, 2013

29. Mahner S, Baasch C, Schwarz J, Hein S, Wölber L, Jänicke F and Milde-Langosch K: C-Fos expression is a molecular predictor of progression and survival in epithelial ovarian carcinoma. $\mathrm{Br}$ J Cancer 99: 1269-1275, 2008.

30. Kusumbe AP, Mali AM and Bapat SA: CD133-expressing stem cells associated with ovarian metastases establish an endothelial hierarchy and contribute to tumor vasculature. Stem Cells 27: 498-508, 2009.

31. Kryczek I, Liu S, Roh M, Vatan L, Szeliga W, Wei S, et al: Expression of aldehyde dehydrogenase and CD133 defines ovarian cancer stem cells. Int J Cancer 130: 29-39, 2012.

32. Burgos-Ojeda D, Rueda BR and Buckanovich RJ: Ovarian cancer stem cell markers: Prognostic and therapeutic implications. Cancer Lett 322: 1-7, 2012.

33. Alvero AB, Fu HH, Holmberg J, Visintin I, Mor L, Marquina CC, Oldtman J, et al: Stem-like ovarian cancer cells can serve as tumor vascular progenitors. Stem Cells 27: 2405-2413, 2009.

34. Liang D, Ma Y, Liu J, Trope CG, Holm R, Nesland JM and Suo Z: The hypoxic microenvironment upgrades stem-like properties of ovarian cancer cells. BMC Cancer 12: 201, 2012.

35. Heddleston JM, Li Z, Lathia JD, Bao S, Hjelmeland AB and Rich JN: Hypoxia inducible factors in cancer stem cells. Br J Cancer 102: 789-795, 2010.

36. Yin G, Alvero AB, Craveiro V, Holmberg JC, Fu HH, Montagna MK, Yang Y, et al: Constitutive proteasomal degradation of TWIST-1 in epithelial-ovarian cancer stem cells impacts differentiation and metastatic potential. Oncogene 32 $39-49,2012$.
37. Cao L, Shao M, Schilder J, Guise T, Mohammad KS and Matei D: Tissue transglutaminase links TGF-beta, epithelial to mesenchymal transition and a stem cell phenotype in ovarian cancer. Oncogene 31: 2521-2534, 2012

38. Jiao J, Huang L, Ye F, Shi M, Cheng X, Wang X, Hu D, et al: Cyclin D1 affects epithelial-mesenchymal transition in epithelial ovarian cancer stem cell-like cells. Onco Targets Ther 6: 667-677, 2013.

39. Yang $\mathrm{H}$ and Chen B: CD147 in ovarian and other cancers. Int $\mathrm{J}$ Gynecol Cancer 23: 2-8, 2013.

40. Yang H, Zou W and Chen B: Overexpression of CD147 in ovarian cancer is initiated by the hypoxic microenvironment. Cell Biol Int 37: 1139-1142, 2013.

41. Millimaggi D, Mari M, D'Ascenzo S, Carosa E, Jannini EA, Zucker S, Carta G, et al: Tumor vesicle-associated CD147 modulates the angiogenic capability of endothelial cells. Neoplasia 9: 349-357, 2007.

42. Zaffryar-Eilot S, Marshall D, Voloshin T, Bar-Zion A, Spangler R, Kessler O, Ghermazien $\mathrm{H}$, et al: Lysyl oxidase-like-2 promotes tumour angiogenesis and is a potential therapeutic target in angiogenic tumours. Carcinogenesis 34: 2370-2379, 2013

43. Su Y, Gao L, Teng L, Wang Y, Cui J, Peng S and Fu S: Id1 enhances human ovarian cancer endothelial progenitor cell angiogenesis via PI3K/Akt and NF- $\mathrm{BB} / \mathrm{MMP}-2$ signaling pathways. J Transl Med 11: 132, 2013

44. Nam EJ, Yoon H, Kim SW, Kim H, Kim YT, Kim JH, Kim JW, et al: MicroRNA expression profiles in serous ovarian carcinoma. Clin Cancer Res 14: 2690-2695, 2008.

45. He J, Jing Y, Li W, Qian X, Xu Q, Li FS, Liu LZ, et al: Roles and mechanism of miR-199a and miR-125b in tumor angiogenesis. PLoS One 8: e56647, 2013.

46. Bamias A, Pignata S and Pujade-Lauraine E: Angiogenesis: A promising therapeutic target for ovarian cancer. Crit Rev Oncol Hematol 84: 314-326, 2012.

47. Ziogas, Gavalas N, Tsiatas M, Tsitsilonis O, Politi E, Terpos E, Rodolakis A, et al: VEGF directly suppresses activation of $\mathrm{T}$ cells from ovarian cancer patients and healthy individuals via VEGF receptor type 2. Int J Cancer 130: 857-864, 2012.

48. Wang X, Zhao X, Wang K, Wu L and Duan T: Interaction of monocytes/macrophages with ovarian cancer cells promotes angiogenesis in vitro. Cancer Sci 104: 516-523, 2013.

49. Lin YS, Nguyen C, Mendoza JL, Escandon E, Fei D, Meng YG and Modi NB: Preclinical pharmacokinetics, interspecies scaling, and tissue distribution of a humanized monoclonal antibody against vascular endothelial growth factor. J Pharmacol Exp Ther 288: 371-378, 1999.

50. Jain R: Antiangiogenic therapy for cancer: current and emerging concepts. Oncology (Williston Park) 19: 7-16, 2005.

51. Burger RA, Brady MF, Bookman MA, Fleming GF, Monk BJ, Huang H, Mannel RS, et al: Incorporation of bevacizumab in the primary treatment of ovarian cancer. N Engl J Med 365: 2473-2483, 2011.

52. Perren TJ, Swart AM, Pfisterer J, Ledermann JA, PujadeLauraine E, Kristensen G, Carey MS, et al: A phase 3 trial of bevacizumab in ovarian cancer. N Engl J Med 365: 2484-2496, 2011

53. Aghajanian C, Blank SV, Goff BA, Judson PL, Teneriello MG, Husain A, Sovak MA, et al: OCEANS: a randomized, doubleblind, placebo-controlled phase III trial of chemotherapy with or without bevacizumab in patients with platinum-sensitive recurrent epithelial ovarian, primary peritoneal, or fallopian tube cancer. J Clin Oncol 30: 2039-2045, 2012.

54. Pujade-Lauraine E, Hilpert F, Weber B, Reuss A, Poveda A, Kristensen G, Sorio R, et al: AURELIA: a randomised phase III trial evaluating bevacizumab combined with chemotherapy for platinum resistant recurrent ovarian cancer. J Clin Oncol 30: (abst, LBA5002), 2012.

55. Garcia A, Hirte H, Fleming G, Yang D, Tsao- Wei D, Roman L, Groshen S, et al: Phase II clinical trial of bevacizumab and low-dose metronomic oral cyclophosphamide in recurrent ovarian cancer: a trial of the California, Chicago, and Princess Margaret Hospital phase II consortia. J Clin Oncol 26: 76-82, 2008

56. McGonigle K, Muntz H, Vuky J, Paley P, Veljovich D, Greer B, Goff BA, et al: Combined weekly topotecan and biweekly bevacizumab in women with platinum-resistant ovarian, peritoneal, or fallopian tube cancer: results of a phase 2 study. Cancer 117: 3731-3740, 2011.

57. Kudoh K, Takano M, Kouta H, Kikuchi R, Kita T, Miyamoto M, Watanabe A, et al: Effects of bevacizumab and pegylated liposomal doxorubicin for the patients with recurrent or refractory ovarian cancers. Gynecol Oncol 122: 233-237, 2011. 
58. O'Malley DM, Richardson DL, Rheaume PS, Salani R, Eisenhauer EL, McCann GA, Fowler JM, et al: Addition of bevacizumab to weekly paclitaxel significantly improves progression-free survival in heavily pretreated recurrent epithelial ovarian cancer. Gynecol Oncol 121: 269-272, 2011.

59. Verschraegen CF, Czok S, Muller CY, Boyd L, Lee SJ, Rutledge T, Blank S, et al: Phase II study of bevacizumab with liposomal doxorubicin for patients with platinum- and taxane-resistant ovarian cancer. Ann Oncol 23: 3104-3110, 2012.

60. Tillmanns TD, Lowe MP, Walker MS, Stepanski EJ and Schwartzberg LS: Phase II clinical trial of bevacizumab with albumin-bound paclitaxel in patients with recurrent, platinumresistant primary epithelial ovarian or primary peritoneal carcinoma. Gynecol Oncol 128: 221-228, 2013.

61. Del Carmen MG, Micha J, Small L, Street DG, Londhe A and McGowan T: A phase II clinical trial of pegylated liposomal doxorubicin and carboplatin plus bevacizumab in patients with platinum-sensitive recurrent ovarian, fallopian tube, or primary peritoneal cancer. Gynecol Oncol 126: 369-374, 2012.

62. Burger R, Sill M, Monk B, Greer B and Sorosky J: Phase II trial of bevacizumab in persistent or recurrent epithelial ovarian cancer or primary peritoneal cancer: a Gynecologic Oncology Group study. J Clin Oncol 25: 5165-5171, 2007.

63. Cannistra S, Matulonis U, Penson R, Hambleton J, Dupont J, Mackey H, Douglas J, et al: Phase II study of bevacizumab in patients with platinum-resistant ovarian cancer or peritoneal serous cancer. J Clin Oncol 25: 5180-5186, 2007.

64. Nimeiri HS, Oza AM, Morgan RJ, Friberg G, Kasza K, Faoro L, Salgia R, et al: Efficacy and safety of bevacizumab plus erlotinib for patients with recurrent ovarian, primary peritoneal, and fallopian tube cancer: a trial of the Chicago, $\mathrm{PMH}$, and California Phase II Consortia. Gynecol Oncol 110: 49-55, 2008.

65. Chambers SK, Clouser MC, Baker AF, Roe DJ, Cui H, Brewer MA, Hatch KD, et al: Overexpression of tumor vascular endothelial growth factor A may portend an increased likelihood of progression in a phase II trial of bevacizumab and erlotinib in resistant ovarian cancer. Clin Cancer Res 16: 5320-5328, 2010.

66. Morgan R, Oza AM, Qin R, Laumann KM, Mackay H, Strevel EL, Welch S, et al: A phase II trial of temsirolimus and bevacizumab in patients with endometrial, ovarian, hepatocellular carcinoma, carcinoid, or islet cell cancer: ovarian cancer (OC) subset - a study of the Princess Margaret, Mayo, Southeast phase II, and California Cancer (CCCP) N01 Consortia NCI\#8233. J Clin Oncol 29: 5015, 2011.

67. Kohn EC, Lee J, Annunziata CM, Minasian LM, Zujewski J, Prindiville SA, Kotz HL, et al: A phase II study of intermittent sorafenib with bevacizumab in bevacizumab-naive epithelial ovarian cancer (EOC) patients. J Clin Oncol 29: 5019, 2011.

68. Tew WP, Colombo N, Ray-Coquard I, Oza A, del Campo J, Scambia G and Spriggs D: VEGF-Trap for patients (pts) with recurrent platinum-resistant epithelial ovarian cancer (EOC): Preliminary results of a randomized, multicenter phase II study. J Clin Oncol 25: 5508, 2007.

69. Colombo N, Mangili G, Mammoliti S, Kalling M, Tholander B, Sternas L, Buzenet G, et al: A phase II study of aflibercept in patients with advanced epithelial ovarian cancer and symptomatic malignant ascites. Gynecol Oncol 125: 42-47, 2012.

70. Friedlander M, Hancock KC, Rischin D, Ma B, et al: A phase II open-label study evaluating pazopanib in patients with recurrent ovarian cancer. Gynecol Oncol 119: 32-37, 2010.

71. Matulonis UA, Berlin S, Ivy P, Tyburski K, Krasner C, Zarwan C, Berkenblit A, et al: Cediranib, an oral inhibitor of vascular endothelial growth factor receptor kinases, is an active drug in recurrent epithelial ovarian, fallopian tube, and peritoneal cancer. J Clin Oncol 27: 5601-5606, 2009.
72. Biagi JJ, Oza AM, ChalCha HI, Grimshaw R, Ellard SL, Lee U, Hirte $\mathrm{H}$, et al: A phase II study of sunitinib in patients with recurrent epithelial ovarian and primary peritoneal carcinoma: an NCIC Clinical Trials Group Study. Ann Oncol 22: 335-340, 2011.

73. Matei D, Sill MW, Lankes HA, DeGeest K, Bristow RE, Mutch D, Yamada SD, et al: Activity of sorafenib in recurrent ovarian cancer and primary peritoneal carcinomatosis: a gynecologic oncology group trial. J Clin Oncol 29: 69-75, 2011.

74. Welch SA, Hirte WHMD, Elit L, Schilder RJ, Wang L, Macalpine K, Wright JJ, et al: Sorafenib in combination with gemcitabine in recurrent epithelial ovarian cancer. A study of the Princess Margaret Hospital Phase II Consortium. Int J Gynecol Cancer 20: 787-793, 2010.

75. Pölcher M, Eckhardt M, Coch C, Wolfgarten M, Kübler K, Hartmann G, Kuhn W, et al: Sorafenib in combination with carboplatin and paclitaxel as neoadjuvant chemotherapy in patients with advanced ovarian cancer. Cancer Chemother Pharmacol 66: 203-207, 2010.

76. Matei D, Ramasubbaiah R, Schilder J, Perkins S, Whalen C, Breen T, Johnson CS, et al: A phase I/II study of topotecan and sorafenib in recurrent, platinum-resistant ovarian cancer: HOG GYN-111. J Clin Oncol 28: 5108, 2010.

77. Ledermann JA, Hackshaw A, Kaye S, Jayson G, Gabra H, McNeish I, Earl H, et al: Randomized phase II placebocontrolled trial of maintenance therapy using the oral triple angiokinase inhibitor BIBF 1120 after chemotherapy for relapsed ovarian cancer. J Clin Oncol 29: 3798-3804, 2011.

78. Buckanovich RJ, Berger R, Sella A, Sikic BI, Shen X, Ramies DA, Smith DC, et al: Activity of cabozantinib (XL184) in advanced ovarian cancer patients (pts): results from a phase II randomized discontinuation trial (RDT). J Clin Oncol 29: 5008, 2011.

79. Schilder RJ, Sill MW, Lee RB, Shaw TJ, Senterman MK, Klein-Szanto AJ, Miner Z, et al: Phase II evaluation of imatinib mesylate in the treatment of recurrent or persistent epithelial ovarian or primary peritoneal carcinoma: a gynecologic oncology group study. J Clin Oncol 26: 3418-3425, 2008.

80. Karlan BY, Oza AM, Richardson GE, Provencher DM, Hansen VL, Buck M, Chambers SK, et al: Randomized, double-blind, placebo-controlled phase II study of AMG 386 combined with weekly paclitaxel in patients with recurrent ovarian cancer. J Clin Oncol 30: 362-371, 2012.

81. Downs Jr LS, Judson PL, Argenta PA, Ghebre R, Geller MA, Bliss RL, Boente MP, et al: A prospective randomized trial of thalidomide with topotecan compared with topotecan alone in women with recurrent epithelial ovarian carcinoma. Cancer 112: 331-339, 2008.

82. Hurteau JA, Brady MF, Darcy KM, McGuire WP, Edmonds P, Pearl ML, Ivanov I, et al: Randomized phase III trial of tamoxifen versus thalidomide in women with biochemicalrecurrent-only epithelial ovarian, fallopian tube or primary peritoneal carcinoma after a complete response to first-line platinum/taxane chemotherapy with an evaluation of serum vascular endothelial growth factor (VEGF): A Gynecologic Oncology Group Study. Gynecol Oncol 119: 444-450, 2010.

83. Bell-McGuinn KM, Matthews CM, Ho SN, Barve M, Gilbert L, Penson RT, LengYel E, et al: A phase II, single-arm study of the anti- $\alpha 5 \beta 1$ integrin antibody volociximab as monotherapy in patients with platinum-resistant advanced epithelial ovarian or primary peritoneal cancer. Gynecol Oncol 121: 273-279, 2011. 